Article

\title{
Synthesis and Performances of Phase Change Microcapsules with a Polymer/Diatomite Hybrid Shell for Thermal Energy Storage
}

\author{
Yanli Sun ${ }^{1,2}$, Rui Wang ${ }^{1,2, *}$, Xing Liu ${ }^{1,2}$, Erqing Dai ${ }^{3}$, Bo Li ${ }^{1,2}$, Shu Fang ${ }^{1,2}$ and Danyang $\mathrm{Li}^{1,2}$ \\ 1 School of Textiles, Tianjin Polytechnic University, No. 399 Bin Shui Xi Road, Xi Qing District, \\ Tianjin 300387, China; yls198959@163.com (Y.S.); liuxing@tjpu.edu.cn (X.L.); 1988li01bo22@163.com (B.L.); \\ fairyfangshu@gmail.com (S.F.); strawberry4173@163.com (D.L.) \\ 2 Key Laboratory of Advanced Textile Composites (Tianjin Polytechnic University), Ministry of Education, \\ Tianjin 300387, China \\ 3 Affiliated Hospital of Logistics University of People's Armed Police Force, Tianjin 300162, China; \\ 13502136445@163.com \\ * Correspondence: wangrui@tjpu.edu.cn; Tel.: +86-022-8395-5527
}

Received: 23 April 2018; Accepted: 28 May 2018; Published: 30 May 2018

\begin{abstract}
The mechanical behavior of phase-change microcapsules (microPCMs) is of vital significance for practical applications in thermal energy storage. Hence, a new type of microPCMs based on an n-octadecane (C18) core and a melamine-urea-formaldehyde (MUF)/diatomite hybrid shell was developed through in situ polymerization. Based on SEM micrographs, most microPCMs exhibited a nearly spherical and smooth microstructure, with broadened particle size distributions. It was confirmed by Fourier transform infrared (FTIR) that successful polymerization of diatomite into the microPCMs occurred, and that additional diatomite had no effect on the core coated by the shell. In addition, the results of the differential scanning calorimeter (DSC) and Atomic Force Microscopy (AFM) demonstrated that the mechanical properties of the microPCMs were remarkably improved by the addition of a moderate amount of diatomite, but that the heat enthalpy and encapsulated efficiency $(\eta)$ decreased slightly. The incorporation of $2 \mathrm{wt} \%$ diatomite resulted in the average Young's modulus of microPCMs, which was 1.64 times greater than those of microPCMs without diatomite. Furthermore, the melting and crystallization enthalpies and the encapsulated efficiency of the microPCMs were as high as $237.6 \mathrm{~J} / \mathrm{g}, 234.4 \mathrm{~J} / \mathrm{g}$ and $77.90 \%$, respectively. The microPCMs with a polymer/diatomite hybrid shell may become the potential materials in the application of thermal energy storage.
\end{abstract}

Keywords: phase-change microcapsules; mechanical behavior; Atomic Force Microscopy; Young's modulus; diatomite

\section{Introduction}

In recent decades, with the rapid development of the economy, energy consumption and demand has increased quickly. However, conventional energy resources are limited, and their application has already led to climate changes, such as air pollution and the greenhouse effect. Therefore, the efficient use of clean and renewable energy resources is a popular research topic. Phase-change materials (PCMs) have been known to be excellent candidates for thermal energy storage because PCMs can absorb and release latent heat within a narrow temperature range during the phase-transition process, and, especially, as they can be reused to reduce energy waste [1,2]. Paraffin waxes, as solid-liquid PCMs, are widely applied because of their merits [3], such as their small amount of supercooling, nontoxicity, non-corrosiveness, chemical stability, and high latent heat energy. However, Paraffin 
waxes show some inherent drawbacks, such as low thermal conductivity and leakage during the melting process, which affects their practical application. To prevent the leakage, controlling the volume change of PCMs during the phase change and increasing the heat-transfer ability can be used as methods to avoid the drawbacks of PCMs. The methods include impregnating PCMs into a polymer matrix [4-6], use of a porous or layered material [7-9], and microencapsulation PCMs. Phase-change microcapsules (microPCMs) have been developed and used. MicroPCMs, with typical core-shell structure, have PCMs as the core surrounded by organic or inorganic material as the shell. MicroPCMs have been used in solar energy storage [10,11], air conditioning [12], building energy conservation [13], and in thermal-regulating fibers and textiles [14].

MicroPCMs with organic shells, such as urea-formaldehyde resin [15], melamine-formaldehyde resin [16], poly (methyl methacrylate) resin [17], and polyuria [18], have been widely studied and applied due to the good structural flexibility and sealing tightness of organic shells. However, there are still some drawbacks of microPCMs with organic shells, such as flammability, poor thermal stabilities, low mechanical strength, and thermal conductivity. Specifically, the mechanical behavior of microPCMs is a key factor in their practical application. Excellent mechanical behavior is not easily satisfied using single organic shells. Therefore, some studies chose to use inorganic shells instead of organic shells. Wang et al. [19] compounded microPCMs, based on paraffin-based binary cores and calcium carbonate shell, via the self-assembly method. Jiang et al. [20] successfully prepared microencapsulated $\mathrm{PCMs}$ with $\mathrm{TiO}_{2} / \mathrm{Fe}_{3} \mathrm{O}_{4}$ hybrid shells as thermoregulatory enzyme carriers. Zhang et al. [21] fabricated microencapsulated PCMs based on an n-octadecane (C18) core and silica shell through interfacial polycondensation. As a result, the microPCMs with inorganic shells present excellent mechanical strength. Nevertheless, the low flexibility leads to poor endurance during practical applications. To overcome the identified shortcomings, several researchers have focused on using an organic-inorganic hybrid shell as it can obtain a synergetic combination of unique properties that exploit the mechanical properties of inorganic shells and the flexibility of organic shells. Inorganic nanoparticles are usually added to microPCMs, such as nanosilver [22], silicon dioxide $\left(\mathrm{SiO}_{2}\right)$ [23], aluminum oxide $\left(\mathrm{Al}_{2} \mathrm{O}_{3}\right)$ [24], graphene [25], and carbon nanotubes (CNTs) [26].

In our previous work [27], we used $\mathrm{O}_{2}$-plasma-modified multiwalled carbon nanotubes (CNTs) to modify the C18-based microPCMs through in situ polymerization. Meanwhile, two different addition methods, the addition of modified CNTs into the emulsion system or into the polymer system, were compared and examined. The results indicated that the mechanical properties of the microPCMs were remarkably improved by the addition of a moderate amount of modified CNTs into the polymer system. The excellent properties of CNTs are beneficial for enhancing the mechanical performance of microPCMs, but the cost of CNTs is slightly higher and pretreatment is required to increase its dispensability in the prepolymer.

Diatomite consists of fossilized remains of diatoms, which is a type of hard-shelled protest [28]. Diatomite possesses high porosity, certain rigidity, and inertness [29]. The main chemical composition of diatomite is silica and diatomite is abundantly available in China, as well as other countries. The price of diatomite is cheap and its source is rich and, thus, diatomite can be used as inorganic nanoparticles and added to microPCMs. However, little work has chosen diatomite to prepare microPCMs with organic-inorganic hybrid shells. In this study, we successfully synthesized microPCMs based on a C18 core and a melamine-urea-formaldehyde (MUF)/diatomite hybrid shell through in situ polymerization, and aimed to achieve improvements in the mechanical properties of microPCMs. The effects of the addition of diatomite on the microstructure, particle size distribution, thermal properties, and mechanical properties of microPCMs have been discussed. 


\section{Experimental}

\subsection{Materials}

C18 was used as a core material and was purchased from Alfa Aesar(China) Chemicals, Co., Ltd. (Shanghai, China)-. Melamine (M), urea (U), and a 37\% formaldehyde solution (F) were used as shell materials. $\mathrm{M}$ and $\mathrm{U}$ were supplied by Tianjin Guangfu Fine Chemical Institution (Tianjin, China), F was supplied by Sigma Aldrich, St. Louis, MO, USA. Sodium dodecyl sulfate (SDS) was used as an emulsifying agent and was obtained from Tianjin Kemiou Chemical Reagent Co., Ltd. (Tianjin, China). Citric acid and triethanolamine were used to control the $\mathrm{pH}$ and were acquired from Tianjin Guangfu Fine Chemical Institution (China). Diatomite (average particle size 1-3 $\mu \mathrm{m}$ ) was provided by Changbai Mountain Korean Autonomous County Xinxin Diatomite Co., Ltd. (Baishan, China).

\subsection{Synthesis of microPCMs with MUF/Diatomite Hybrid Shell}

Microencapsulated C18, with a MUF/diatomite hybrid shell, were synthesized by in situ polymerization. As shown in Figure 1, the microencapsulation procedure included three key stages: (1) Preparation of the MUF prepolymer and addition of diatomite, (2) C18 emulsification, and (3) polymerization of the shell materials.

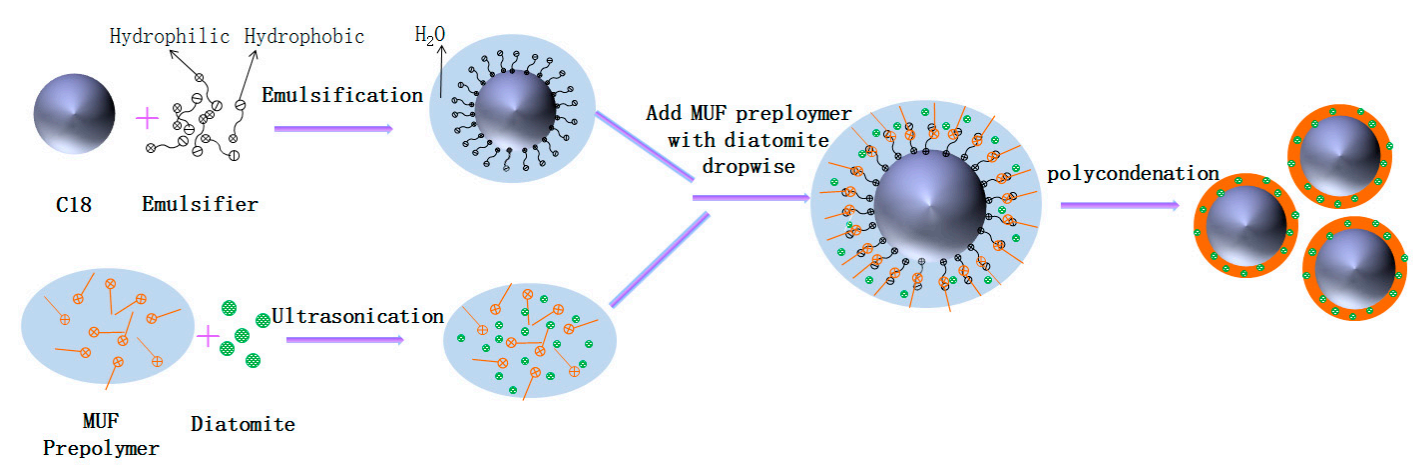

Figure 1. Synthetic scheme for phase-change microcapsules (microPCMs) with melamine-urea-formaldehyde (MUF)/diatomite hybrid shells via in situ polymerization.

Firstly, $3.81 \mathrm{~g}$ of melamine, $6.89 \mathrm{~g}$ of aqueous formaldehyde, and $70 \mathrm{~mL}$ of distilled water were mixed in a beaker. The $\mathrm{pH}$ value of the mixture was adjusted to 8.5 with triethanolamine. The reaction was continued at $70{ }^{\circ} \mathrm{C}$ for $20 \mathrm{~min}$ under mechanical stirring. Then, the system was cooled to room temperature and $0.92 \mathrm{~g}$ of urea was added to the MUF prepolymer. A certain amount of diatomite were added to the MUF prepolymer solution and ultrasonically dispersed for $10 \mathrm{~min}$. Secondly, $15 \mathrm{~g}$ of C18 was emulsified at $1000 \mathrm{rpm}$ in a $10 \mathrm{wt} \%$ SDS aqueous solution at $40{ }^{\circ} \mathrm{C}$ for $30 \mathrm{~min}$ to a generate a stable oil-in-water (O-W) emulsion. Thirdly, the $\mathrm{pH}$ value of the emulsion was controlled at 5 with $13 \mathrm{wt} \%$ citri acid solution, the emulsion was continuously stirred at $300 \mathrm{rpm}$, and the temperature was adjusted to $75{ }^{\circ} \mathrm{C}$. The MUF preploymer dispersing diatomite was, subsequently, added dropwise to the emulsion and the system continued to react for $3.5 \mathrm{~h}$. Finally, microPCMs, with MUF/diatomite hybrid shells, were obtained by filtration and dried at room temperature. Table 1 shows the specific process parameters. 
Table 1. Preparation of phase-change microcapsules (microPCMs) with melamine-urea-formaldehyde (MUF)/diatomite hybrid shells.

\begin{tabular}{lccccccc}
\hline & microPCMs & S0 & S1 & S2 & S3 & S4 & S5 \\
\hline \multirow{3}{*}{ emulsion system } & N-octadecane (g) & 15 & 15 & 15 & 15 & 15 & 15 \\
& SDS (wt \%) & 10 & 10 & 10 & 10 & 10 & 10 \\
& Distilled water (mL) & 90 & 90 & 90 & 90 & 90 & 90 \\
\hline \multirow{3}{*}{ Pre-polymer system } & Melamine (g) & 3.81 & 3.81 & 3.81 & 3.81 & 3.81 & 3.81 \\
& Formaldehyde (g) & 6.89 & 6.89 & 6.89 & 6.89 & 6.89 & 6.89 \\
& Urea (g) & 0.92 & 0.92 & 0.92 & 0.92 & 0.92 & 0.92 \\
& Distilled water(mL) & 70 & 70 & 70 & 70 & 70 & 70 \\
\hline & Diatomite (\%) & 0 & 0.5 & 1 & 1.5 & 2 & 3 \\
\hline
\end{tabular}

\subsection{Characterization}

\subsubsection{Fourier Transform Infrared}

Fourier transform infrared (FTIR) spectra characterized the chemical structure of the C18, MUF shell. MicroPCMs were obtained using a FTIR spectroscopy (TENSOR37, Bruker, Saarbrücken, Germany) in the range of 4000 to $500 \mathrm{~cm}^{-1}$ at a resolution of $4 \mathrm{~cm}^{-1}$ using $\mathrm{KBr}$ pellets at room temperature.

\subsubsection{Scanning Electron Microscopy Observation and Particle Size Analysis}

The surface morphologies and the wall thickness of the microPCMs were observed using a field emission scanning electron microscope (FESEM, S-4800, Hitachi, Tokyo, Japan) at an accelerating voltage of $10.0 \mathrm{kV}$. The specimens were sprayed with gold prior to observation. Evaluation method of wall thickness is as follows: Firstly, the microPCMs were adhered to a sample platform with a conductive adhesive and, then, the microPCMs on the sample platform were cut by a sharp blade in a liquid nitrogen environment. Finally, the cross-section of the microPCMs was observed using FESEM and measured by Image-Pro Plus analysis software (6.0). The particle size distribution was examined with Image-Pro Plus analysis software and over 200 microPCMs were counted.

\subsubsection{Differential Scanning Calorimeter}

The phase-change properties of the $\mathrm{C} 18$ and the microPCMs were analyzed using a differential scanning calorimeter (DSC) (Netzsch 204F1, Netzsch Group, Bavaria, Germany) in the temperature range of -20 to $80^{\circ} \mathrm{C}$ at a heating/cooling rate of $5{ }^{\circ} \mathrm{C} / \mathrm{min}$ under a nitrogen atmosphere.

\subsubsection{Thermalgravimetric Analysis}

The thermal stability of the $\mathrm{C} 18$ and the microPCMs was performed using a thermalgravimetric analysis (TG) (Netzsch STA 409 PC/PG TG-DTA, Netzsch Group, Bavaria, Germany) in the temperature range of 25 to $600{ }^{\circ} \mathrm{C}$ at a heating/cooling rate of $10^{\circ} \mathrm{C} / \mathrm{min}$ under a nitrogen atmosphere.

\subsubsection{Mechanical Properties}

The mechanical properties of the microPCMs were examined using Atomic Force Microscopy (AFM) (CSPM5500, Benyuan, Beijing, China) [15,30]. The Young's modulus (E) of the samples was calculated from the force curve measured by AFM. The sample was glued on a disk with epoxy, and then spherical and clean particles were chosen to be tested using the optical system. AFM topographic images were acquired using the non-contact mode, and the force curve was obtained using the contact mode. The ranges of the scan areas was $2 \mu \mathrm{m} \times 2 \mu \mathrm{m}$ and scan frequency was $1 \mathrm{~Hz}$. The probe (AC240TS, Olympus, Tokyo, Japan) material was Si, with an elastic modulus of 150 GPa, a Poisson's 
ratio of 0.17 , and an elastic coefficient of the probe of $1.73 \mathrm{~N} / \mathrm{m}$. The shape of the cantilever was rectangle and the tip had a 3-sided shape.

The test process of the sample force curve is depicted in Figure 2a-d. Figure 2a shows as the piezoelectric ceramic voltage increases, the sample starts to rise, with no contact between the probe and the sample. The sample begins to contact with the probe and continues to rise (Figure $2 b$ ). Then, as can be seen in Figure 2c, the cantilever deforms as the sample continuously rises. According to the deformation of the cantilever, the load, $f$, can be calculated. The sample has a certain deformation under the action of $f$. After the deformation of the cantilever reaches a certain point, that is $f$ reaches a certain value, the sample starts to be withdrawn and unloaded continuously (Figure 2d).

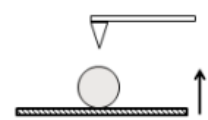

(a)

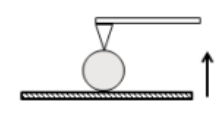

(b)

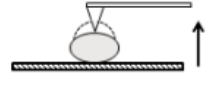

(c)

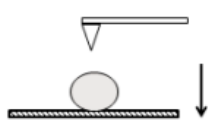

(d)

Figure 2. The test process of phase-change microcapsules' (microPCMs) force curve: (a) the sample starts to rise, (b) the sample begins to contact with the probe, (c) maximum deformation of cantilever, and (d) the sample drop.

\section{Results and Discussion}

\subsection{FTIR Spectra}

Figure 3 presents the FTIR spectra of the MUF shell, C18, microPCMs (S0 and S4), and diatomite. In the spectrum of the MUF shell (Figure 3a), an absorption peak at $3431 \mathrm{~cm}^{-1}$ was identified as the stretching vibrations of $\mathrm{O}-\mathrm{H}$ and $\mathrm{N}-\mathrm{H}$, the peaks at 1588 and $1339 \mathrm{~cm}^{-1}$ corresponded to the stretching vibrations of $\mathrm{C}-\mathrm{N}$ and $\mathrm{C}=\mathrm{N}$, and the peak at $812 \mathrm{~cm}^{-1}$ ascribed to the bending vibration of the triazine ring. It can be seen in Figure $3 \mathrm{~b}$ that the two strong absorption peaks at 2923 and $2851 \mathrm{~cm}^{-1}$ were caused by the $\mathrm{C}-\mathrm{H}$ stretching vibrations, the absorbance at $1466 \mathrm{~cm}^{-1}$ was attributed to the $-\mathrm{CH}_{2}$ and $-\mathrm{CH}_{3}$ deformation vibrations, and that the $-\mathrm{CH}_{2}$ in-plane rocking vibrations were found at approximately $719 \mathrm{~cm}^{-1}$. After microencapsulation, the characteristic peaks of the MUF shell and C18 appeared in the spectrum of the microPCMs (S0 and S4) without new peaks, and the location of the peaks maintained the same level. There were just physical combinations existing between the core and the shell. A characteristic peak at $1017 \mathrm{~cm}^{-1}$ in the diatomite spectrum (Figure 3e) was ascribed to the stretching vibration peak of $\mathrm{Si}-\mathrm{O}-\mathrm{Si}$; this peak also appeared in the spectrum of the $\mathrm{S} 4$. It can be inferred that successful polymerization of diatomite into the microPCMs and addition of diatomite had no effect on the core coated by the shell.

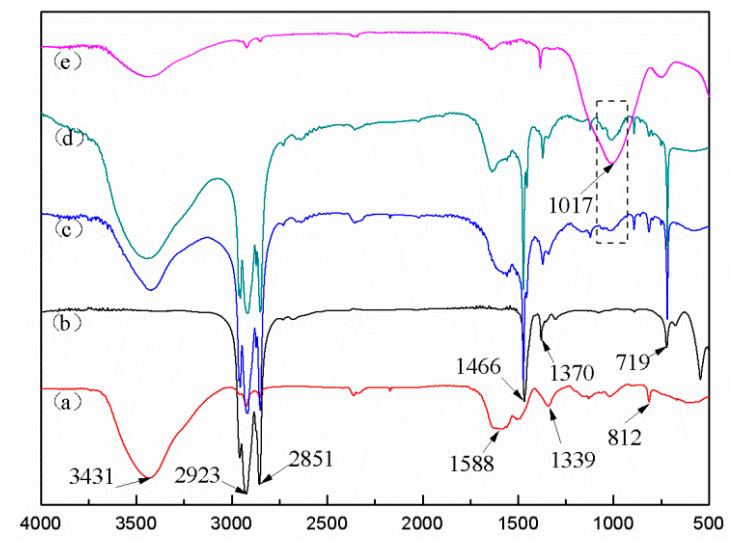

Figure 3. Fourier transform infrared (FTIR) spectra of $\mathrm{C} 18$ and phase-change microcapsules (microPCMs): (a) Melamine-urea-formaldehyde (MUF) shell, (b) C18, (c) S0, (d) S4, and (e) diatomite. 


\subsection{Morphology, Wall Thicknesses, and Particle Size Distribution}

Figure 4 shows the microstructures and surface morphology of the microPCMs (S0, S1, S2, S3, S4 and S5), and the wall thicknesses of the $\mathrm{S} 0$ and S4. It can be observed that most the microPCMs were close to spherical, which had smooth surfaces and dispersed without any agglomeration. Meanwhile, the SEM micrographs show that the surfaces of the microPCMs had some dimples. These dimples were ascribed to the space shrinkage of the $\mathrm{C} 18$ phase, changing from the melting state to the crystal state. Furthermore, it is notable that the small dimples became fewer and more inconspicuous as the amount of diatomite increased (Figure 4a-e). However, when diatomite continued to increase, ruptured microPCMs appeared (Figure 4f). This may suggest that the addition of a moderate amount of diatomite could enhance the mechanical strength of the shell and will hardly deform [31]. Excessive amounts of diatomite led to an agglomeration of particles and had a negative influence on the adsorption of the shell on the surface of the core [32], which was not beneficial to the core coated by the shell.

Figure $4 \mathrm{~g}-\mathrm{h}$ shows the wall thickness of the microPCMs (S0 and S4), which is approximately 0.31 and $0.32 \mu \mathrm{m}$, respectively. This indicates that the addition of diatomite had less of an effect on the wall thickness.
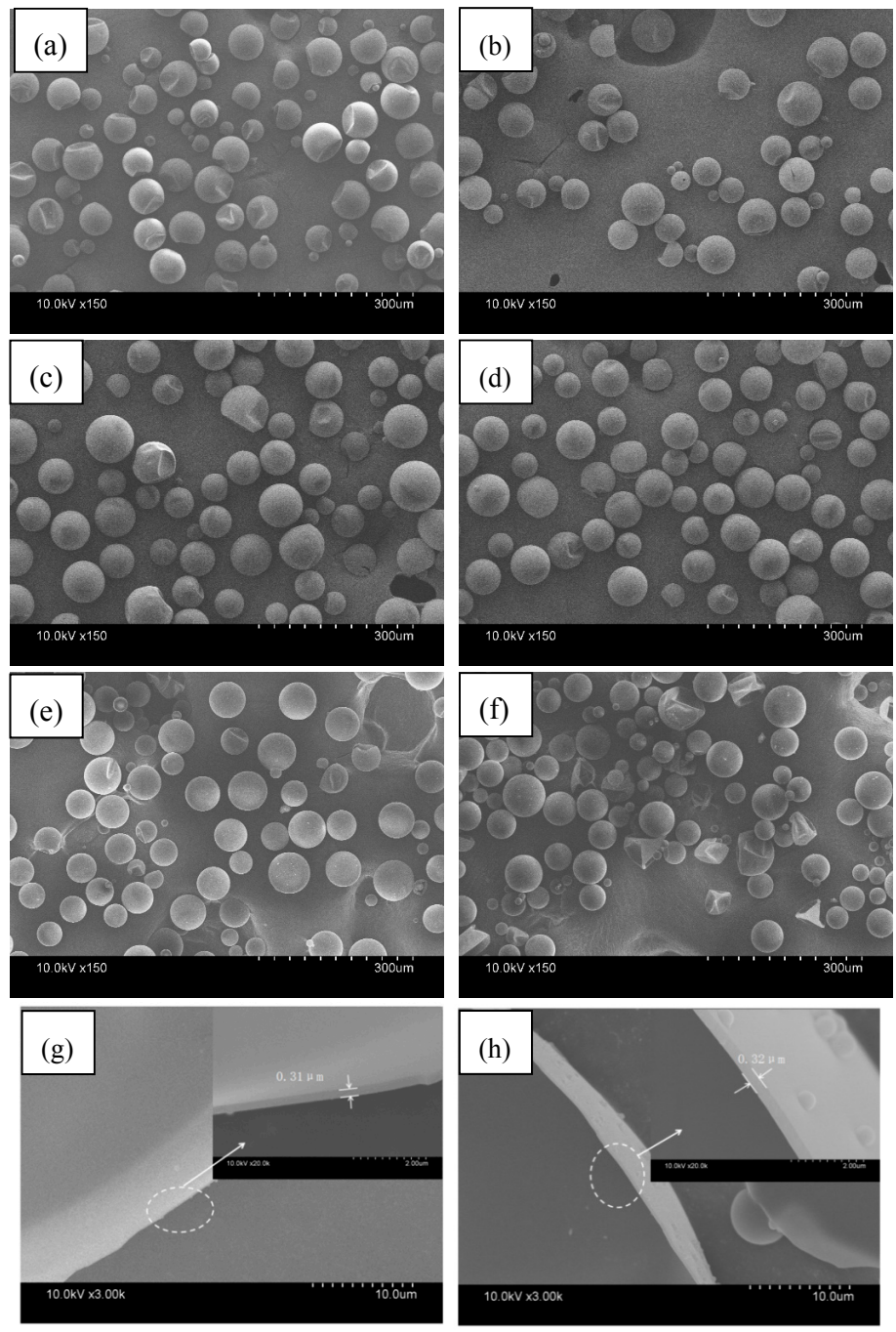

Figure 4. Scanning electron microscopy images of phase-change microcapsules (microPCMs) and damaged microPCMs with different amounts of diatomite added: (a-g) S0, (b) S1, (c) S2, (d) S3, (e-h) S4, and (f) S5. 
Figure 5 presents the particle size distribution of the microPCMs and Table 2 lists the average particle size. It can be found that the size of the samples was mainly distributed in the range of 10 100 $\mu \mathrm{m}$, and had broadened particle size distributions. The average particle size of S0 was approximately $40.26 \mu \mathrm{m}$, whereas the average particle sizes of S1, S2, S3, S4, and S5 were measured to be $41.31,42.34,41.96,42.81$, and $42.56 \mu \mathrm{m}( \pm 2 \mu \mathrm{m}$, the measuring error), respectively. There was almost no difference between the average particle sizes of the microPCMs with diatomite and the microPCMs without diatomite. This showed that the adding of diatomite had little impact on the particle size of the microPCMs. The results agree with our previous work [27].

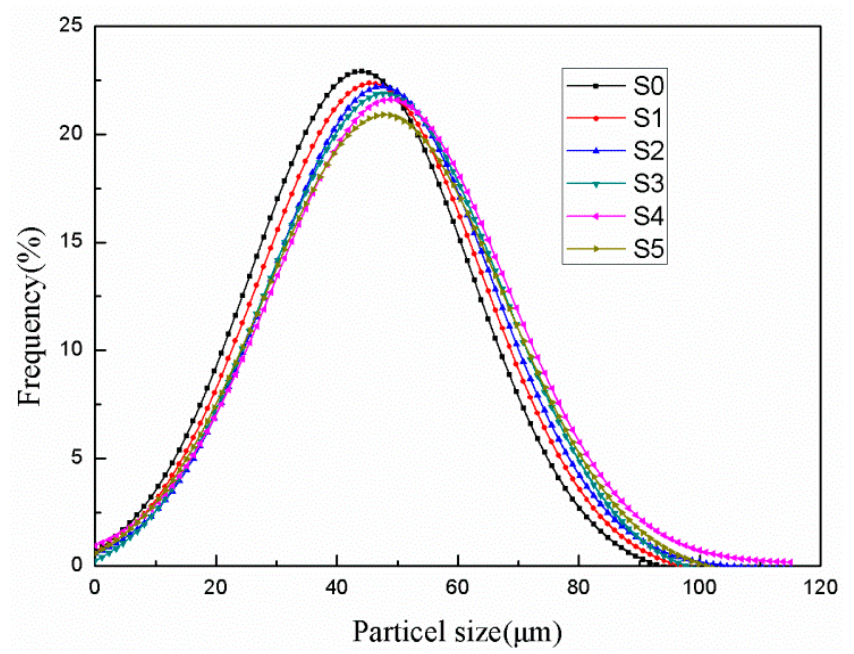

Figure 5. Particle size distributions of phase-change microcapsules (microPCMs) with different amounts of diatomite.

\subsection{Phase-Change Properties and Thermal Storage Capability}

The phase-change behaviors of the $\mathrm{C} 18$ and microPCMs (S0, S1, S2, S3, S4 and S5) were evaluated by DSC and the resulting thermograms are presented in Figure 6 . The melting and crystallization parameters obtained from DSC are listed in Table 2. Compared with the $\mathrm{C} 18$, the melting temperature $\left(T_{m}\right)$ of the microPCMs moved towards lower temperatures and the crystallization temperature $\left(T_{c}\right)$ of the microPCMs shifted to slightly higher temperatures, as shown in Figure 6 and Table 2. Similar phenomena has been reported elsewhere [33]. This result was ascribed to two reasons; one was that the $\mathrm{C} 18$ was microencapsulated to increase the surface areas and the other was that the motion was confined inside a narrow space. Hence, the heat/cool transportation became faster from the outside to the core.

It is observed, in Figure 6, that C18 presents an endothermic peak in the melting process and an exothermic peak in the crystallization process, while an endothermic peak and multiple exothermic peaks are presented in the phase-change process of the microPCMs. Moreover, the multiple exothermic peaks become more obvious at increasing amounts of diatomite. There are two PCMs crystallizations in the cooling process, namely, homogeneous and heterogeneous crystallization [34,35]. When microencapsulated, C18 was coated by the MUF shell and the inner shell can act as a nucleating agent, which generates heterogeneous nucleation crystallization and multiple peaks appear in the solidifying curves. Diatomite added to the shell can also play a role as nuclei and the heterogeneous crystallization peak increased and, thus, the above results appeared [36]. These facts also revealed that the addition of diatomite improved the heterogeneous nucleation crystallization of C18. 

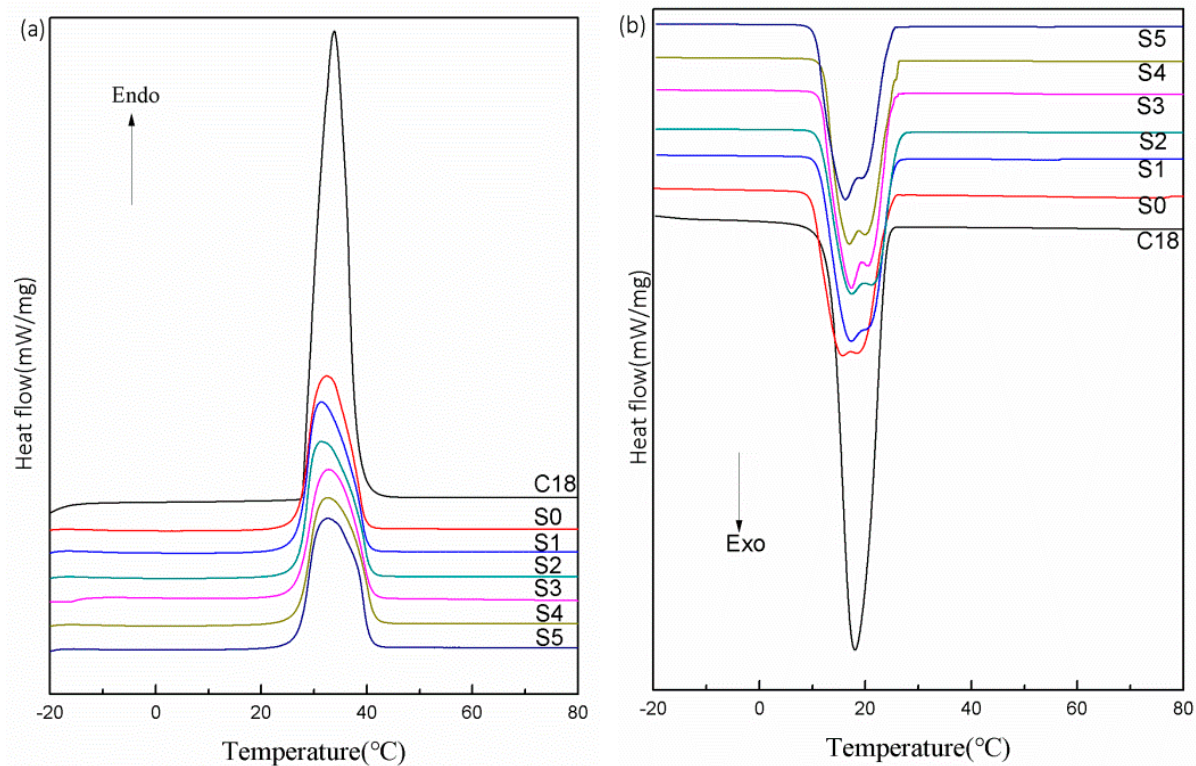

Figure 6. Differential scanning calorimeter (DSC) thermograms of C18, S0, S1, S2, S3, S4, and S5: (a) Heating thermograms and (b) cooling thermograms.

In addition, the heat enthalpy and encapsulated efficiency $(\eta)$ are also crucial parameters to evaluate the microPCMs. The specific values are provided in Table 2. The encapsulated efficiency, $\eta$, was evaluated using the following formula [37]:

$$
\eta=\frac{\Delta H_{m, \text { microPCMs }}+\Delta H_{c, \text { microPCMs }}}{\Delta H_{m, P C M s}+\Delta H_{c, P C M s}} \times 100 \%
$$

where $\triangle H_{m \text {,microPCMs }}$ and $\triangle H_{c, \text { microPCMs }}$ are the melting enthalpy and crystallization enthalpy of the microPCMs; and $\Delta H_{m, P C M s}$ and $\Delta H_{c, P C M s}$ are the melting enthalpy and crystallization enthalpy of C18, respectively.

Table 2. The average particle size and phase change properties of the C18 and phase-change microcapsules (microPCMs), incorporated with different amounts of diatomite.

\begin{tabular}{ccccccc}
\hline Samples & Average Particle Size $(\boldsymbol{\mu m})$ & $\boldsymbol{T}_{m}\left({ }^{\circ} \mathbf{C}\right)$ & $\Delta \boldsymbol{H}_{m}(\mathrm{~J} / \mathrm{g})$ & $\boldsymbol{T}_{\boldsymbol{c}}\left({ }^{\circ} \mathrm{C}\right)$ & $\boldsymbol{\Delta} \boldsymbol{H}_{\boldsymbol{c}}(\mathrm{J} / \mathrm{g})$ & $\eta(\%)$ \\
\hline C18 & 0 & 27.5 & 307.1 & 25.5 & 298.8 & 0 \\
S0 & 40.26 & 26.9 & 250.1 & 25.8 & 255.6 & 83.46 \\
S1 & 41.31 & 26.8 & 245.8 & 25.9 & 248.1 & 81.52 \\
S2 & 42.34 & 26.9 & 240.2 & 25.8 & 241.4 & 79.49 \\
S3 & 41.96 & 26.7 & 243.9 & 25.9 & 241.1 & 80.05 \\
S4 & 42.81 & 26.8 & 237.6 & 25.8 & 234.4 & 77.90 \\
S5 & 43.56 & 26.8 & 227.3 & 25.9 & 228.2 & 75.18 \\
\hline
\end{tabular}

Obviously, the melting enthalpy $\left(\Delta H_{m}\right)$ and the crystallization enthalpy $\left(\Delta H_{c}\right)$ of the microPCMs were dramatically lower in comparison to the $\mathrm{C} 18$, and the $\Delta H_{m}, \Delta H_{\mathcal{c}}$, and $\eta$ were slightly reduced with an increase in diatomite contents, as seen in Table 2. In the DSC scanning temperature range, the MUF shell and diatomite did not undergo any phase-change, with only the $\mathrm{C} 18$ being able to store and release the latent heat. It is notable that the core-shell weight ratio was a key factor influencing heat enthalpy. When $3 \mathrm{wt} \%$ of diatomite was added, the heat enthalpy and $\eta$ still reached more than $225 \mathrm{~J} / \mathrm{g}$ and $75 \%$, respectively, which satisfied the applied requirements for heat storage and exchange. 


\subsection{Thermal Stability}

The thermal decomposition properties of the $\mathrm{C} 18$ and microPCMs (S0, S1, S2, S3, S4, and S5) were studied by TG and the resulting thermograms are presented in Figure 7. From Figure 7, it is obvious that the $\mathrm{C} 18$ exhibits a typical one-step thermal decomposition process. The $\mathrm{C} 18$ started to lose weight at $130{ }^{\circ} \mathrm{C}$ and the degradation process ended up at about $200{ }^{\circ} \mathrm{C}$. By contrast, all the microPCMs samples show a two-stage thermal decomposition process. The first step of weight loss, in the range of $180-350{ }^{\circ} \mathrm{C}$, was caused by vaporization of the $\mathrm{C} 18$ from the microPCMs and its further degradation. The second step of weight loss, at about $350-420^{\circ} \mathrm{C}$, was attributed to the MUF shell pyrolysis. We can easily find that the onset degradation temperature of the microPCMs was almost $50{ }^{\circ} \mathrm{C}$ higher than that of the $\mathrm{C} 18$. This means that the shell provided an effective barrier and could delay the rapid $\mathrm{C} 18$ decomposition. Furthermore, the starting thermal degradation temperature was delayed to $181.2^{\circ} \mathrm{C}$ for S0 and to $182.3,183.5,184.3,184.7$, and $183.6^{\circ} \mathrm{C}$ for S1, S2, S3, S4, and S5, respectively. Thus, the above results indicate that the starting thermal degradation temperature had no obvious change as the addition of diatomite and the thermal stability was almost unaffected by the hybrid shell.

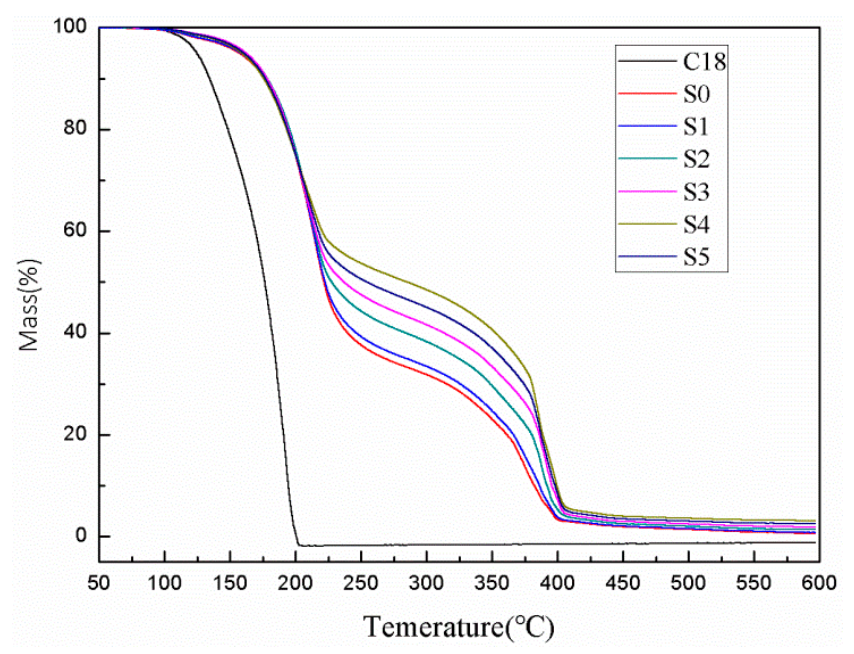

Figure 7. Thermogravimetry spectra of $\mathrm{C} 18, \mathrm{~S} 0, \mathrm{~S} 1, \mathrm{~S} 2, \mathrm{~S} 3, \mathrm{~S} 4$, and S5.

\subsection{Mechanical Properties}

The surface profile of the $\mathrm{S} 0$ and $\mathrm{S} 4$ were further elucidated by AFM, as shown in Figure 8 . The $\mathrm{S} 0$ exhibits rather smooth outlines. However, the surface of the $\mathrm{S} 4$ presents some small protuberances due to the embedded diatomite.
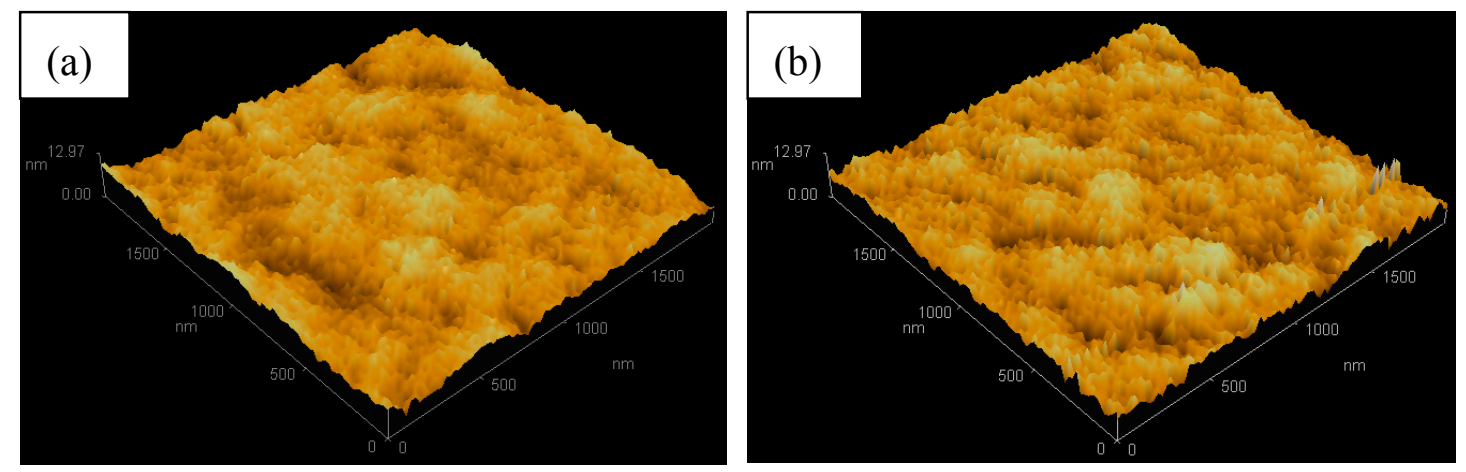

Figure 8. Atomic Force Microscopy (AFM) images of the surfaces of the phase-change microcapsules (microPCMs): (a) S0 and (b) S4. 
In order to further confirm that adding diatomite could improve the mechanical properties of microPCMs, the mechanical properties of the microPCMs were tested by AFM. The effect of the addition of diatomite on the mechanical properties of the microPCMs was investigated by comparison with $E$. E was obtained by analyzing the force curve and calculated by using the Hertz model [30]. The specific calculation formula is as follows:

$$
f=\frac{\pi}{2} \frac{E}{1-v^{2}} \tan \alpha \delta^{2}
$$

where $f$ is the force exerted by the probe on the microcapsules, $\mathrm{nN}$; $v$ is the Poisson ratio with a value of $0.33 ; \alpha$ is the probe half angle with a value of $36^{\circ}$; and $\delta$ is the sample penetration.

A hard, smooth, and non-deformable material was selected as a standard sample for testing, and the $f$ and $\delta$ could be calculated by analyzing the standard sample. We choose the mica film as the standard sample, and the force curve of the mica film is shown in Figure 9. The $x$-axis is the displacement of the piezoelectric ceramics in the $\mathrm{Z}$ direction, which presents the rising height of the sample; the $y$-axis presents the cantilever deflection; and a, b, c, and d represents the four processes of the force curve test. The sample begins to contact with the probe at point $b$ and the cantilever deforms and loads the sample.

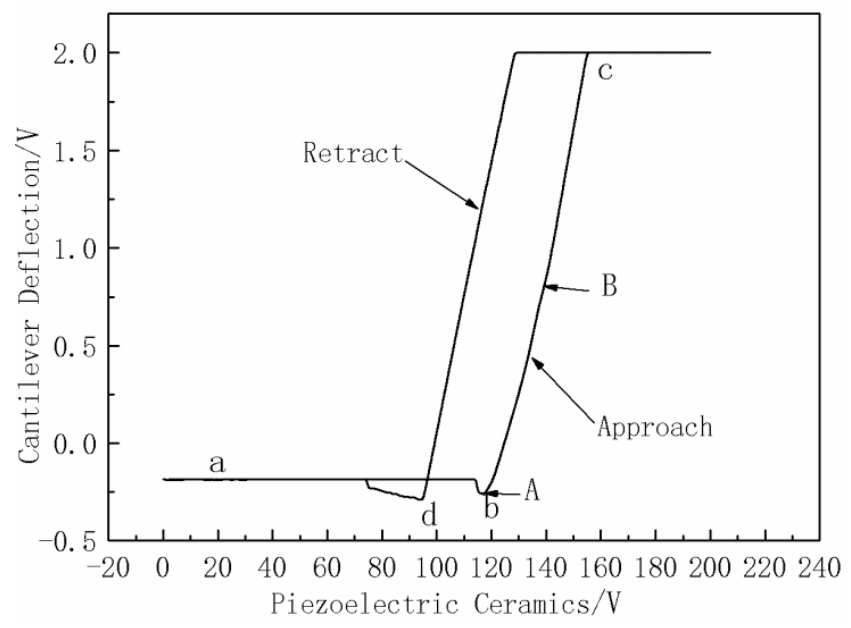

Figure 9. The force curve of prototype.

When the probe starts to touch the standard sample (A) and until the cantilever deflection is $1 \mathrm{~V}(\mathrm{~B})$, the rising height of the standard sample is $H$. $H$ is expressed in Equation (3), where $Z$ is the scaling coefficient of the scanner, with a value of $10.811 \mathrm{~V} / \mathrm{nm} ; X_{A}$ and $X_{B}$ is the coordinate point corresponding to the $X$ axis, respectively.

$$
H=(X A-X B) \times Z
$$

$f$ is calculated as in Equation (4):

$$
f=k \cdot H
$$

Similar force curves could be obtained by testing microPCMs samples. When the probe starts to touch the microPCMs sample $\left(\mathrm{A}^{\prime}\right)$ and until the cantilever deflection is $1 \mathrm{~V}\left(\mathrm{~B}^{\prime}\right)$, the rising height of the microPCMs sample is $H^{\prime}$ and the force acting on the microPCMs samples is $f . H^{\prime}$ is acquired by Equation (3) and the $\delta$ due to the exerted $f$ is evaluated as Equation (5). Then, E could be obtained using the Hertz model.

$$
\delta=H-H^{\prime}
$$

Table 3 gives the maximum, minimum, and average values of the effective test results of the microPCMs E. As seen in Table 3, the dates measured by this method show large discreteness. Similar 
results has been obtained in reference $[15,30]$. The wide dispersion of the test results were mainly related to the test method. The test of the AFM force curve is affected by various factors, such as the surface morphologies and defects of the microPCMs, probe stiffness, loading rate, and indentation depth, which can result in a significant dispersion of the test results. However, by comparing the average value of $E$, we found that the Young's modulus of the microPCMs with diatomite increased significantly. The average Young's modulus of the microPCMs with 2 wt \% diatomite (S4) was 942.85 MPa, which was 1.64 times greater than those of the microPCMs without diatomite (S0). This value indicates that the assembled diatomite could change the Young's modulus of the MUF shell and significantly strengthen the microPCMs, even in relatively low mass percentages. Diatomite was evenly dispersed into the shell of the microPCMs. When the microPCMs was subjected to external force, the diatomite could produce a stress concentration effect, which absorbed energy and prevented further deformation and the rupture of the microPCMs. A similar phenomenon has been observed in reference [27,38].

Additionally, we discovered that the Young's modulus increased initially and then decreased slightly with increasing diatomite content. It was very difficult to have microPCMs with excellent mechanical properties when the diatomite content became higher. Extensive agglomeration of diatomite particles occurred in the MUF shell when the amount of diatomite reached a value, leading to the uneven distribution of diatomite in the shell and poor interfacial adhesion with the shell. As a result, some formed shell might have loose structures and rupture easily. These results suggest that microPCMs incorporated with a moderate amount of diatomite could improve the mechanical properties and exhibits a good potential application for energy storage.

Table 3. The Young's modulus of phase-change microcapsules (microPCMs) incorporated with different amounts of diatomite.

\begin{tabular}{ccccccc}
\hline E/MPa & S0 & S1 & S2 & S3 & S4 & S5 \\
\hline Maximum & 1870.90 & 1970.20 & 2476.95 & 2874.94 & 3065.39 & 2583.59 \\
Minimum & 102.09 & 94.56 & 157.48 & 189.57 & 197.45 & 161.58 \\
Average & 575.49 & 589.43 & 768.23 & 903.26 & 942.85 & 773.05 \\
\hline
\end{tabular}

\section{Conclusions}

A novel kind of microencapsulated PCMs with MUF/diatomite hybrid shells were successfully synthesized through in situ polymerization. The effects of diatomite particles and contents on the FTIR, microstructure, particle size distribution, thermal properties, and mechanical properties of microPCMs were investigated. Results showed that most of the microPCMs had a spherical and smooth microstructure, were dispersed without any agglomeration, and had broadened particle size distributions. Moreover, the addition of diatomite had no effect on the core coated by the shell. The investigation of the heat storage performance of the microPCMs indicated that an increase in diatomite content could slightly reduce the heat enthalpy and $\eta$. According to the result of the mechanical properties, the incorporation of diatomite greatly enhanced the Young's modulus of the MUF shell and significantly strengthened the microPCMs. When $2 \mathrm{wt} \%$ diatomite was incorporated, the melting and crystallization enthalpies and the encapsulated efficiency of the microPCMs were as high as $237.6 \mathrm{~J} / \mathrm{g}$, $234.4 \mathrm{~J} / \mathrm{g}$ and $77.90 \%$, respectively. Additionally, the average Young's modulus of S4 was $942.85 \mathrm{MPa}$, which was 1.64 times greater than those of the microPCMs without diatomite. The microPCMs with a polymer/diatomite hybrid shell exhibited a high heat enthalpy and good mechanical properties, which is a promising prospect in the fields of thermal energy storage, temperature-regulating textiles, and building energy conservation.

Author Contributions: Y.S. and R.W. conceived and designed the experiments; Y.S. and B.L. performed the experiments; Y.S. and X.L. analyzed the data; E.D. contributed reagents/materials; Y.S. wrote the paper; F.S. and D.L. revised the paper. 
Acknowledgments: The authors would especially like to thank Tianjin Research Program of Application Foundation and Advanced Technology (NO. 15JCZDJC38400) for financial support.

Conflicts of Interest: The authors declare no conflict of interest.

\section{References}

1. Jiang, Z.; Yang, W.; He, F.; Xie, C.; Fan, J.; Wu, J.; Zhang, K. Modified phase change microcapsules with calcium carbonate and graphene oxide shell for enhanced energy storage and leakage prevention. ACS Sustain. Chem. Eng. 2018, 6, 5182-5191. [CrossRef]

2. Wang, T.; Jiang, Y.; Huang, J.; Wang, S. High thermal conductive paraffin/calcium carbonate phase change microcapsules based composites with different carbon network. Appl. Energy 2018, 218, 184-191. [CrossRef]

3. Hussien, H.; Abed, A.; Abdulmunem, A. An experimental investigation of using aluminum foam matrix integrated with paraffin wax as a thermal storage material in a solar heater. In Proceedings of the 2nd Sustainable Renewable Energy Conference, Baghdad, Iraq, 26-27 November 2016.

4. Dorigato, A.; Ciampolillo, M.V.; Cataldi, A.; Bersani, M.; Pegoretti, A. Polyethylene wax/EPDM blends as shape-stabilized phase change materials for thermal energy storage. Rubber Chem. Technol. 2017, 90, 575-584. [CrossRef]

5. Fredi, G.; Dorigato, A.; Pegoretti, A. Multifunctional glass fiber/polyamide composites with thermal energy storage/release capability. Express Polym. Lett. 2018, 12, 349-364. [CrossRef]

6. Fredi, G.; Dorigato, A.; Fambri, L.; Pegoretti, A. Wax confinement with carbon nanotubes for phase changing epoxy blends. Polymers 2017, 9, 405. [CrossRef]

7. Yang, J.; Zhang, E.; Li, X.; Zhang, Y.; Qu, J.; Yu, Z. Cellulose/graphene aerogel supported phase change composites with high thermal conductivity and good shape stability for thermal energy storage. Carbon 2016, 98, 50-57. [CrossRef]

8. Fredi, G.; Dorigato, A.; Fambri, L.; Pegoretti, A. Multifunctional epoxy/carbon fiber laminates for thermal energy storage and release. Compos. Sci. Technol. 2018, 158, 101-111. [CrossRef]

9. Dorigato, A.; Canclini, P.; Unterberger, S.; Pegoretti, A. Phase changing nanocomposites for low temperature thermal energy storage and release. Express Polym. Lett. 2017, 11, 738-752. [CrossRef]

10. Liu, Z.; Chen, Z.; Yu, F. Microencapsulated phase change material modified by graphene oxide with different degrees of oxidation for solar energy storage. Sol. Energy Mater. Sol. Cells 2018, 174, 453-459. [CrossRef]

11. Yang, Y.; Kuang, J.; Wang, H.; Song, G.; Liu, Y.; Tang, G. Enhancement in thermal property of phase change microcapsules with modified silicon nitride for solar energy. Sol. Energy Mater. Sol. Cells 2016, 151, 89-95. [CrossRef]

12. Zheng, L.; Zhang, W.; Liang, F. A review about phase change material cold storage system applied to solar-powered air-conditioning system. Adv. Mech. Eng. 2017, 9, 1687814017705844. [CrossRef]

13. Lei, J.; Yang, J.; Yang, E. Energy performance of building envelopes integrated with phase change materials for cooling load reduction in tropical singapore. Appl. Energy 2016, 162, 207-217. [CrossRef]

14. Shin, Y.; Yoo, D.I.; Son, K. Development of thermoregulating textile materials with microencapsulated phase change materials (PCM). IV. performance properties and hand of fabrics treated with PCM microcapsules. Appl. Polym. Sci. 2005, 97, 910-915. [CrossRef]

15. Li, W.; Zhang, X.; Wang, X.; Niu, J. Preparation and characterization of microencapsulated phase change material with low remnant formaldehyde content. Mater. Chem. Phys. 2007, 106, 437-442. [CrossRef]

16. Cao, F.; Yang, B. Supercooling suppression of microencapsulated phase change materials by optimizing shell composition and structure. Appl. Energy 2014, 113, 1512-1518. [CrossRef]

17. Ma, Y.; Chu, X.; Li, W.; Tang, G. Preparation and characterization of poly(methyl methacrylateco-divinylbenzene) microcapsules containing phase change temperature adjustable binary core materials. Sol. Energy 2012, 86, 2056-2066. [CrossRef]

18. Lu, S.; Shen, T.; Xing, J.; Song, Q.; Shao, J.; Zhang, J.; Xin, C. Preparation and characterization of cross-linked polyurethane shell microencapsulated phase change materials by interfacial polymerization. Mater. Lett. 2017, 211, 36-39. [CrossRef]

19. Wang, T.; Wang, S.; Luo, R.; Zhu, C.; Akiyama, T.; Zhang, Z. Microencapsulation of phase change materials with binary cores and calcium carbonate shell for thermal energy storage. Appl. Energy 2016, 171, 113-119. [CrossRef] 
20. Jiang, B.; Wang, X.; Wu, D. Fabrication of microencapsulated phase change materials with $\mathrm{TiO}_{2} / \mathrm{Fe}_{3} \mathrm{O}_{4}$ hybrid shell as thermoregulatory enzyme carriers: A novel design of applied energy microsystem for bioapplications. Appl. Energy 2017, 201, 20-33. [CrossRef]

21. Zhang, H.; Sun, S.; Wang, X.; Wu, D. Fabrication of microencapsulated phase change materials based on $\mathrm{N}$-octadecane core and silica shell through interfacial polycondensation. Colloids Surf. A 2011, 389, 104-117. [CrossRef]

22. Song, Q.; Li, Y.; Xing, J.; Hu, J.; Marcus, Y. Thermal stability of composite phase change material microcapsules incorporated with silver nano-particles. Polymer 2007, 48, 3317-3323. [CrossRef]

23. Yin, D.; Liu, H.; Ma, L.; Zhang, Q. Fabrication and performance of microencapsulated phase change materials with hybrid shell by in situ polymerization in pickering emulsion. Polym. Adv. Technol. 2015, 26, 613-619. [CrossRef]

24. Jiang, X.; Luo, R.; Peng, F.; Fang, Y.; Akiyama, T.; Wang, S. Synthesis, characterization and thermal properties of paraffin microcapsules modified with nano- $\mathrm{Al}_{2} \mathrm{O}_{3}$. Appl. Energy 2015, 137, 731-737. [CrossRef]

25. Wu, B.; Zheng, G.; Chen, X. Effect of graphene on the thermophysical properties of melamine-urea-formaldehyde/N-hexadecane microcapsules. RSC Adv. 2015, 5, 74024-74031. [CrossRef]

26. Cui, W.; Xia, Y.; Zhang, H.; Xu, F.; Zou, Y.; Xiang, C.; Chu, H.; Qiu, S.; Sun, L. Microencapsulation of phase change materials with carbon nanotubes reinforced shell for enhancement of thermal conductivity. Mater. Sci. Eng. Conf. Ser. 2017, 182, 012015. [CrossRef]

27. Sun, Y.; Wang, R.; Liu, X.; Li, M.; Yang, H.; Li, B. Improvements in the thermal conductivity and mechanical properties of phase-change microcapsules with oxygen-plasma-modified multiwalled carbon nanotubes. J. Appl. Polym. Sci. 2017, 134, 45269. [CrossRef]

28. Xu, B.; Li, Z. Paraffin/diatomite/multi-wall carbon nanotubes composite phase change material tailor-made for thermal energy storage cement-based composites. Energy 2014, 72, 371-380. [CrossRef]

29. Li, X.; Sanjayan, J.; Wilson, J. Fabrication and stability of form-stable diatomite/paraffin phase change material composites. Energy Build. 2014, 76, 284-294. [CrossRef]

30. Giro-Paloma, J.; Oncins, G.; Barreneche, C.; Martínez, M.; Fernández, I.; Cabeza, L. Physico-chemical and mechanical properties of microencapsulated phase change material. Appl. Energy 2013, 109, 441-448. [CrossRef]

31. Zhao, J.; Yang, Y.; Li, Y.; Zhao, L.; Wang, H.; Song, G.; Tang, G. Microencapsulated phase change materials with $\mathrm{TiO}_{2}$-doped pmma shell for thermal energy storage and UV-shielding. Sol. Energy Mater. Sol. Cells 2017, 168, 62-68. [CrossRef]

32. Chen, L.; Zhang, L.; Tang, R.; Lu, Y. Synthesis and thermal properties of phase-change microcapsules incorporated with nano alumina particles in the shell. J. Appl. Polym. Sci. 2012, 124, 689-698. [CrossRef]

33. Wang, H.; Zhao, L.; Song, G.; Tang, G.; Shi, X. Organic-inorganic hybrid shell microencapsulated phase change materials prepared from $\mathrm{SiO}_{2} / \mathrm{TiC}$-stabilized pickering emulsion polymerization. Sol. Energy Mater. Sol. Cells 2018, 175, 102-110. [CrossRef]

34. Zhang, X.; Wang, X.; Wu, D. Design and synthesis of multifunctional microencapsulated phase change materials with silver/silica double-layered shell for thermal energy storage, electrical conduction and antimicrobial effectiveness. Energy 2016, 111, 498-512. [CrossRef]

35. Zhao, L.; Luo, J.; Wang, H.; Song, G.; Tang, G. Self-assembly fabrication of microencapsulated N-octadecane with natural silk fibroin shell for thermal-regulating textiles. Appl. Therm. Eng. 2016, 99, 495-501. [CrossRef]

36. Huang, Y.; Zhang, H.; Wan, X.; Chen, D.; Chen, X.; Ye, X.; Ouyang, X.; Qin, S.; Wen, H.; Tang, J. Carbon nanotube-enhanced double-walled phase-change microcapsules for thermal energy storage. J. Mater. Chem. A 2017, 5, 7482-7493. [CrossRef]

37. Li, M.; Liu, T.; Hu, L.; Wang, Y.; Gao, L. Fabrication and properties of microencapsulated paraffin@SiO $\mathrm{S}_{2}$ phase change composite for thermal energy storage. ACS Sustain. Chem. Eng. 2013, 1, 374-380. [CrossRef]

38. Li, M.; Chen, M.; Wu, Z. Enhancement in thermal property and mechanical property of phase change microcapsule with modified carbon nanotube. Appl. Energy 2014, 127, 166-171. [CrossRef]

(C) 2018 by the authors. Licensee MDPI, Basel, Switzerland. This article is an open access article distributed under the terms and conditions of the Creative Commons Attribution (CC BY) license (http:/ / creativecommons.org/licenses/by/4.0/). 